\title{
Pengembangan Infrastruktur Jaringan Berbasis Nirkabel Ke Jaringan Berteknologi GPEN (Gigabit Passive Ethernet Network) Di Kampus IAIN Bengkulu
}

\author{
Candra Wijaya $^{1 *}$, Hari Aspriyono ${ }^{2,}$ Abdussalam Al Akbar ${ }^{3}$ \\ ${ }^{1}$ Informatika Universitas Dehasen Bengkulu \\ Bengkulu, chandra.wjya@gmail.com \\ ${ }^{2}$ Informatika Universitas Dehasen Bengkulu \\ Bengkulu, hari.aspriyono@gmail.com \\ ${ }^{3}$ Informatika Universitas Dehasen Bengkulu \\ Bengkulu,akbarabenk@unived.ac.id
}

\begin{abstract}
Abstrak
The purpose of this research is to build an interconnection network using GPEN (Gigabit Passive Ethernet Network) technology so as to provide convenience for network admin users in managing, controlling, and maintaining each client, making it easy for network technicians when a breakdown occurs, and Providing easy client user authentication. in the area (PUSKOM) IAIN Bengkulu. The research method used is research and development research, the research method used to aim at developing, producing products and waiting for the effectiveness of the research method. Developing a wireless-based network, namely a point-to-point radio to a network with GPEN technology (Gigabit Passive Ethernet Network) as a switch and router that supports gigabit ports and to control and monitor bandwidth on each client. Better network quality and efficiency so that activities such as browsing, uploading and downloading are faster.
\end{abstract}

Keywords : Technology, GPEN, Internet

Information :

1. Candidate for Computer Science

2. Supervisor

\section{Pendahuluan}

Dalam perkembangan teknologi komputer yang semakin pesat maka perkembangan jaringan komputer pun dituntut juga untuk mengikuti perkembangan teknologi tersebut, hal ini terlihat dari tingginya kebutuhan jaringan komputer yang pada saat ini telah banyak digunakan diperguruan tinggi, perkantoran, sekolah, hotel, dan perumahan. kebutuhan manusia semakin bertambah, terutama kebutuhan akan penggunaan jaringan internet untuk berbagai macam kegiatan.

Jaringan komputer merupakan interkoneksi beberapa komputer dengan tujuan untuk dapat saling berkomunikasi, berdasarkan media transmisi data yang digunakan dapat menggunakan kabel atau tanpa kabel (wireless). GPEN atau Gigabit Passive Ethernet Network konsep baru ini hampir sama seperti GPON tetapi dengan alternatif ethernet sebagai media transmisi. Ini akan memungkinkan pengguna yang lebih kecil untuk memberikan layanan serupa seperti GPON dengan biaya yang jauh lebih kecil, implementasi langsung \& menggunakan infrastruktur saat ini.

Pada (PUSKOM) IAIN Bengkulu telah memiliki jaringan berbasis nirkabel sebagai media aksesnya, akan tetapi Perancangan internet menggunakan media akses point to point banyak memiliki kekurangan baik dari sisi gangguan sinyal atau gelombang serta penghalang antara client server seperti banggunan gedung, pepohonan, dan ketinggian tergantung dari alat yang digunakan dan jarak saat konfigurasi internet.

Konsep GPEN ini bisa menjadi solusi pengguna internet baik untuk pengguna skala kecil atau besar. Instalasi GPEN lebih mudah dan harga yang relatif murah dibandingkan menggunakan GPON. Untuk media akses dari client ke server bisa menggunakan kabel ethernet atau menggunakan fiber optik. Untuk konsep GPEN ada beberapa perangkat yang nantinya bisa digunakan. Diantaranya terdapat GPEN11, GPEN21, GPeR, NetPower. Konsep GPEN tidak membutuhkan GPON OLT, Splitter dll. Tetapi hanya membutuhkan switch dan router mikrotik saja.

Berdasarkan latar belakang yang telah diuraikan maka diperlukan sebuah penelitian yang mampu memperoleh solusi atas permasalah tersebut yaitu mengembangkan infrastruktur jaringan menggunakan konsep GPEN sebagai media aksesnya. Maka penulis tertarik untuk mengambil judul "Pengembangan Infrastruktur Jaringan Berbasis Nirkabel Ke Jaringan Berteknologi GPEN (Gigabit Passive Ethernet Network) di Kampus IAIN Bengkulu"

\section{TINJAUAN PUSTAKA}

\section{Pengembangan}


Pengembangan sistem (systems development) adalah menyusun suatu sistem yang baru untuk menggantikan system yang lama secara keseluruhan atau memperbaiki sistem yang telah ada [1].

Sedangkan pengembangan artinya ide, rancangan proses, cara, perbuatan mengembangkan [2] . Dan konsep pengembangan adalah rancangan mengembangkan sesuatu yang sudah ada dalam rangka meningkatkan kualitas lebih maju

Berdasarkan pengertian pengembangan yang telah diuraikan yang dimaksud dengan pengembangan adalah suatu proses untuk menjadikan potensi yang ada menjadi sesuatu yang lebih baik dan berguna sedangkan penelitian dan pengembangan adalah suatu proses atau langkahlangkah untuk mengembangkan suatu produk atau menyempurnakan produk yang telah ada menjadi produk yang dapat dipertanggung jawabkan.

\section{Infrastruktur Jaringan}

Network infrastructure atau infrastruktur jaringan merupakan sebuah kumpulan sistem komputer yang saling berhubungan, dihubungkan oleh berbagai macam bagian dari sebuah arsitektur telekomunikasi. Secara khusus, infrastruktur ini mengacu pada organisasi dan berbagai bagian konfigurasi dari jaringan komputer individu sampai pada router, kabel, wireless access point, switch, backbone, network protocol, dan network access methodologies [3] .

Infrastruktur Teknologi yang selanjutnya disebut infrastruktur adalah perangkat keras, perangkat lunak dan fasilitas yang menjadi penunjang utama untuk menjalankan sistem, aplikasi, komunikasi data, pengolahan dan penyimpanan data [4] .

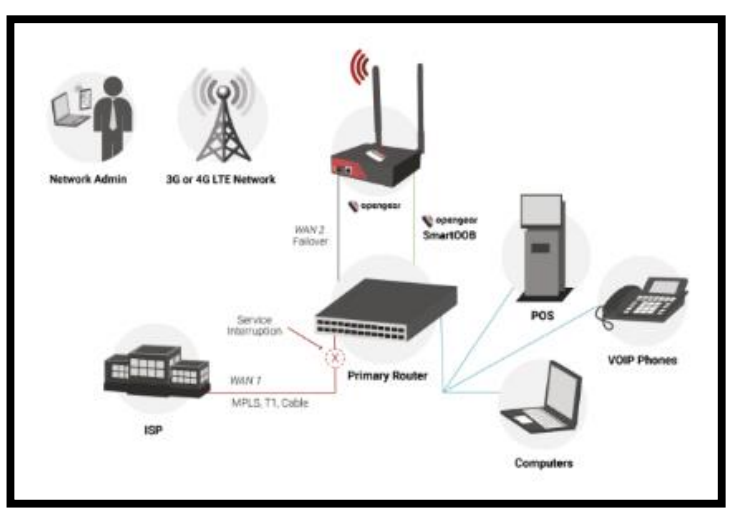

Gambar 1. Infrastruktur Jaringan

\section{Teknologi}

Teknologi adalah metode ilmiah untuk mencapai tujuan praktis ilmu pengetahuan terapan. Teknologi adalah sarana untuk menyediakan barang-barang yang dibutuhkan bagi keberlangsungan hidup manusia.
Penggunaan teknologi sangat membantu perkembangan umat manusia sehingga mencuatkan nilai-nilai baru di dalam kehidupan bermasyarakat [5].

Teknologi Informasi adalah suatu teknologi yang digunakan untuk mengolah data, termasuk memproses, mendapatkan, menyusun, menyimpan, memanipulasi data dalam berbagai cara untuk menghasilkan informasi yang berkualitas, yaitu informasi yang relevan, akurat dan tepat waktu, yang digunakan untuk keperluan pribadi, bisnis, dan pemerintahan dan merupakan informasi yang strategis untuk pengambilan keputusan. Teknologi ini menggunakan seperangkat komputer untuk mengolah data, sistem jaringan untuk menghubungkan satu komputer dengan komputer yang lainnya sesuai dengan kebutuhan, dan teknologi telekomunikasi digunakan agar data dapat disebar dan diakses secara global [6] .

\section{Jaringan Komputer}

Jaringan komputer adalah kumpulan komputer dan alat-alat yang saling dihubungkan bersama menggunakan media komunikasi tertentu [7]. Jaringan komputer adalah sebuah kumpulan komputer, printer dan peralatan lainnya yang terhubung dalam satu kesatuan. Informasi dan data memungkinkan pengguna jaringan komputer dapat saling bertukar dokumen dan data, mencetak pada printer secara bersama-sama menggunakan hardware/software yang terhubung dengan jaringan [8].

Jaringan komputer adalah jaringan telekomunikasi yang memungkinkan antar komputer untuk saling berkomunikasi bertukar data [9]. Sedangkan Jaringan komputer didefinisikan sebagai sekumpulan komputer yang terhubung satu dengan yang lainnya menggunakan media tertentu sehingga memungkinkan diantara komputer tersebut untuk berinteraksi, bertukar data, dan berbagi peralatan Bersama [10]

Dari pengertian diatas, dapat disimpulkan bahwa jaringan komputer adalah sekumpulan komputer dan peralatannya yang saling berhubungan dengan menggunakan media komunikasi tertentu sehingga antara komputer satu dengan yang lainya dapat berbagi data dan sumber daya yang dimiliki.menjalankan sistem, aplikasi,

\section{GPEN (Gigabit Passive Ethernet Network)}

GPEN atau Gigabit Passive Ethernet Network, adalah konsep baru yang dikeluarkan oleh Mikrotik. Konsep ini hampir sama seperti GPON tetapi dengan alternatif ethernet sebagai media transmisi. Ini akan memungkinkan pengguna yang lebih kecil untuk memberikan layanan serupa seperti GPON dengan biaya yang jauh lebih kecil, implementasi langsung \& menggunakan infrastruktur saat ini. Konsep Mikrotik GPEN diharapkan bisa menjadi solusi interkoneksi 
dengan biaya yang lebih murah dibandingkan menggunakan GPON [11].

Untuk konsep GPEN ada beberapa perangkat yang nantinya bisa digunakan. Diantaranya terdapat GPEN11, GPEN21, GPeR, NetPower. Konsep GPEN tidak membutuhkan GPON OLT, Splitter dll. Tetapi hanya membutuhkan switch dan router mikrotik saja. Contoh topologi yang direkomendasikan untuk konsep GPEN adalah sebagai berikut :

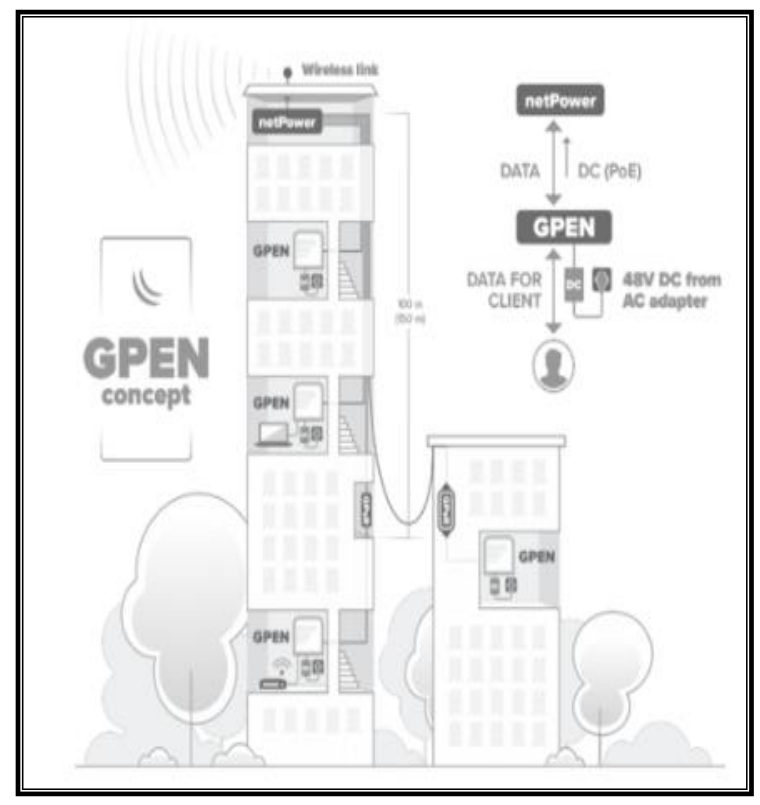

Gambar 2. Topologi GPEN

\section{Perangkat-perangkat GPEN}

\section{A. GPEN11 dan GPEN21}

GPEN11 dan GPEN21 sudah didesain untuk wallmount. Perbedaannya, GPEN11 memiliki 2 port ethernet, 1 ethernet digunakan untuk data ke arah client dan 1 ethernet digunakan untuk POE Output. Sedangkan GPEN21, memiliki 2 port ethernet dan 1 tambahan SFP untuk Fiber Optic. Selain itu, GPEN21 menggunakan SwitchOS atau SWOS Ada beberapa fitur di dalam GPEN21 seperti :

\section{- GPEN link fault detection}

- Basic Traffic Shaping

- VLAN support

- Interface management and monitoring front

- SNMP reporting

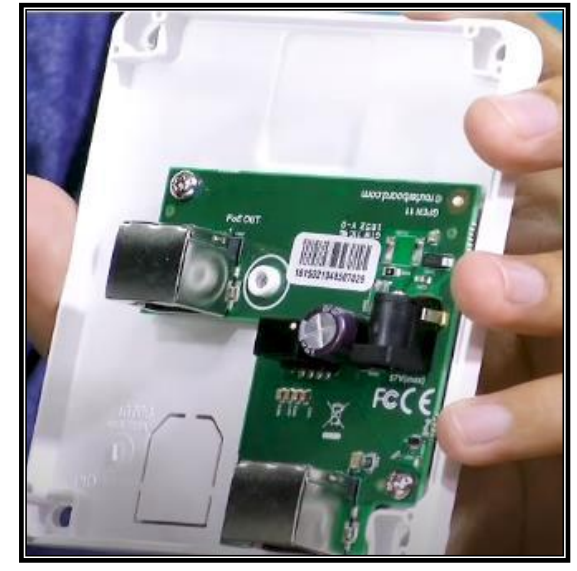

Gambar 3. GPEN11

\section{B. GPER}

Gigabit Passive Ethernet Repeater juga termasuk dalam konsep GPEN. Bisa difungsikan untuk menambah jarak PoE yang bisa dijangkau. Unit GPeR memungkinkan untuk memperpanjang kabel ethernet dengan hop tambahan hingga 1.500 meter. Jarak maksimal kabel ethernet CAT6 antara dua perangkat GPeR hingga $210 \mathrm{~m}$ (tergantung pada kualitas kabel). GPeR ini bisa menjadi solusi untuk keterbatasan jarak pada kabel ethernet [11].

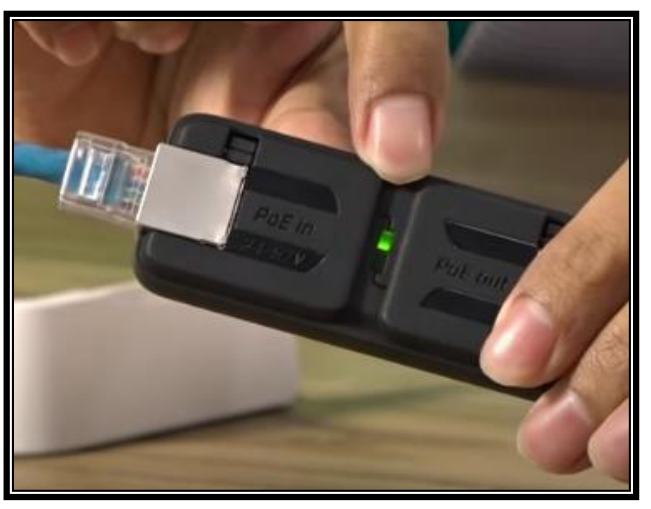

Gambar 4. GPER

\section{Netpower}

Jika GPON mempunyai splitter dan base stations, pada konsep GPEN terdapat netPower. Ada 15 port ethernet PoE-IN yang bisa di provide dari GPEN (GPEN11 atau GPEN21) atau bisa juga dari PoE injektor yang biasa digunakan. Terdapat 1 port PoE-Out yang bisa digunakan untuk menghidupkan perangkat Access-Point Outdoor, CCTV dan perangkat ini bekerja sebagai switch dan support dengan PoE-IN Reverse [11]. 


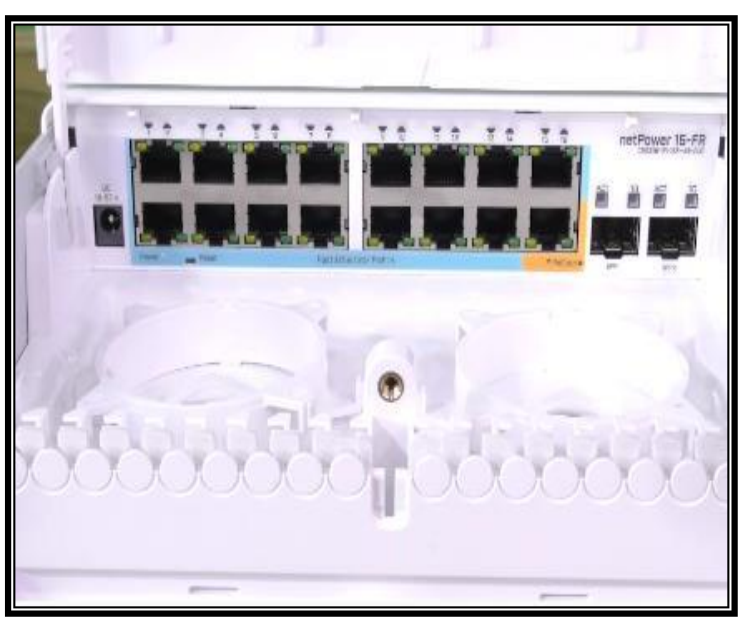

Gambar 5. NetPower

\section{METODE PENELITIAN}

\section{Metode penelitian}

Metode penelitian research and development adalah metode penelitian yang digunakan untuk bertujuan melakukan pengembangan, menghasilkan produk dan menunggu keefektifan [12]. metode research \& Development $(\mathrm{R} \& \mathrm{D})$ sama maknanya dengan metode penelitian pengembangan. Research \& Development adalah pendekatan penelitian untuk mengasilkan produk baru atau menyempurnakan produk yang sudah ada [13].

Metode penelitian yang digunakan yaitu penelitian research and development, Metode yang dilakukan dalam penelitian ini yaitu dengan menggunakan pengembangan langsung untuk mengembangkan jaringan berbasis nirkabel yaitu radio point to point ke jaringan berteknologi GPEN (Gigabit Passive Ethernet Network) sebagai switch dan router yang support port gigabit dan untuk mengontrol serta memonitoring bandwith pada masing-masing client .

\section{Metode Pengumpulan Data}

\section{A. Metode Observasi}

adalah metode pengumpulan data dimana penulis mengumpulkan data dengan pengamatan langsung pada objek yang diteliti yakni mengembangkan jaringan berbasis nirkabel yaitu radio point to point ke jaringan berteknologi GPEN (Gigabit Passive Ethernet Network) sebagai switch dan router yang support port gigabit dan untuk mengontrol serta memonitoring bandwith pada masing-masing client .

\section{B. Metode Studi Labolatorium}

adalah suatu metode yang melakukan uji coba langsung terhadap Software SwitchOS / Winbox v 3.37 yang di pasang pada sistem operasi windows untuk melakukan control/monitoring bandwith pada jaringan setiap client.

\section{Metode Kepustakaan}

adalah suatu metode pengumpulan data dimana penulis mencari dan membaca serta mempelajari bukubuku yang berhubungan dengan masalah yang diangkat yaitu pengembangan atau membangun jaringan berteknologi GPEN (Gigabit Passive Ethernet Network).

\section{Metode perancangan sistem}

\section{A. Analisa Sistem Aktual}

Sebagaimana telah diuraikan dalam latar belakang, masalah jaringan berbasis nirkabel yaitu radio point to point pada (PUSKOM) IAIN Bengkulu sudah memiliki jaringan memiliki jaringan berbasis nirkabel sebagai media aksesnya, akan tetapi Perancangan internet menggunakan media akses point to point banyak memiliki kekurangan baik dari sisi gangguan sinyal atau gelombang serta penghalang antara client server seperti banggunan gedung, pepohonan, dan ketinggian tergantung dari alat yang digunakan dan jarak saat konfigurasi internet. Adapun jaringan internet yang ada pada (PUSKOM) IAIN Bengkulu dapat dilihat pada gambar dibawah ini.
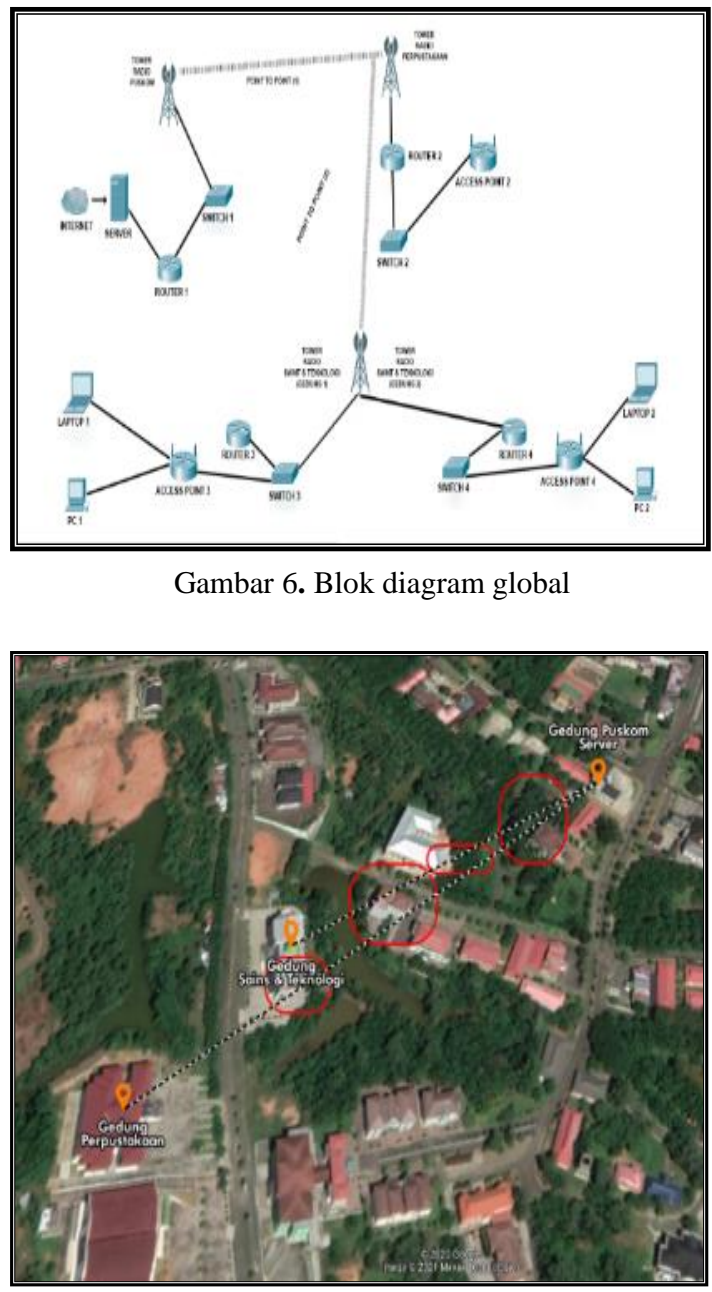

Gambar 7. Analisa Obstacle 


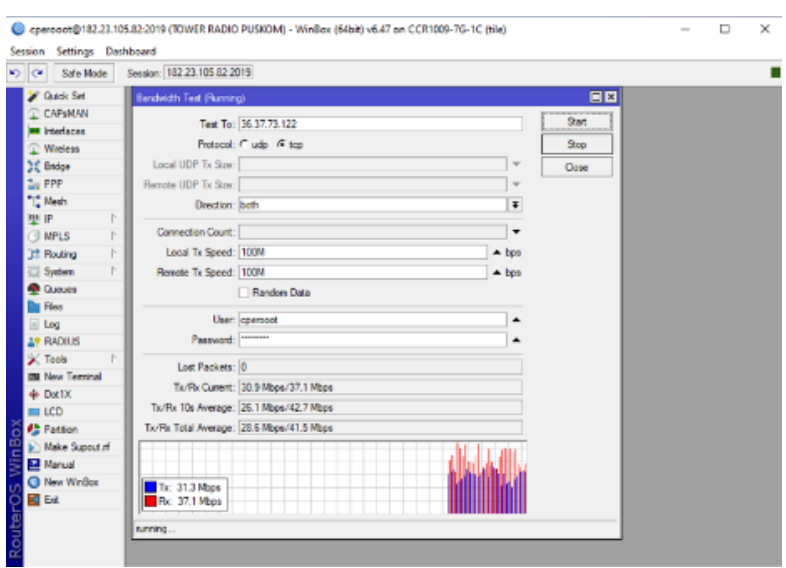

Gambar 8. Analisa Traffic Bandwithtest Akses Radio

Tabel 1. Analisa Biaya Akses Radio Link

\begin{tabular}{|c|c|c|c|c|}
\hline \multicolumn{5}{|c|}{ Biaya Akses Puskom Ke Sains Teknologi } \\
\hline No & Description & Qty & Harga & Total \\
\hline 1 & $\begin{array}{l}\text { Cambium EpMP 5Ghz } \\
\text { Force } 180 \text { Intergrated }\end{array}$ & 2 & 1.500 .000 & 3.000 .000 \\
\hline \multirow[t]{2}{*}{2} & $\begin{array}{l}\text { TPLink WR840N Router } \\
\& \text { Wirelles }\end{array}$ & 1 & 150.000 & 150.000 \\
\hline & & & Total & 3.150 .000 \\
\hline \multicolumn{5}{|c|}{ Biaya Akses Puskom Ke Perpustakaan } \\
\hline 1 & $\begin{array}{l}\text { Cambium EpMP 5Ghz } \\
\text { Force } 180 \text { Intergrated }\end{array}$ & 2 & 1.500 .000 & 3.000 .000 \\
\hline \multirow[t]{2}{*}{2} & $\begin{array}{l}\text { TPLink WR840N Router } \\
\& \text { Wirelles }\end{array}$ & 1 & 150.000 & 150.000 \\
\hline & & & $\begin{array}{l}\text { Total } \\
\text { Sub Total }\end{array}$ & $\begin{array}{l}3.150 .000 \\
6.300 .000\end{array}$ \\
\hline \multicolumn{5}{|c|}{ Biaya Maintenance } \\
\hline 1 & Crimping Tool Cat 6 & 1 & 240.000 & 240.000 \\
\hline 2 & $\begin{array}{l}\text { LAN Tester Wire Tracker } \\
\text { JW-360 }\end{array}$ & 1 & 140.000 & 140.000 \\
\hline \multirow[t]{2}{*}{3} & Cambium EpMP 5Ghz & 1 & 1.500 .000 & 1.500 .000 \\
\hline & & & Sub Total & 1.880 .000 \\
\hline
\end{tabular}

Tabel 2. Analisa Biaya Akses Ethernet (GPEN)

\begin{tabular}{llccr}
\hline \multicolumn{5}{c}{ Media Transmisi Link Akses Ke Server } \\
\hline No & \multicolumn{1}{c}{ Description } & Qty & Harga & Total \\
\hline 1 & Kabel LAN Outdoor & & & \\
& STP/FTP Cat6 1 Roll & 2 & 700.000 & 1.400 .000 \\
& Mikrotik GpeR Gigabit & 5 & 295.000 & 1.475 .000 \\
& Passive Ethernet Repater & 5 & Total & $\mathbf{2 . 8 7 5 . 0 0 0}$ \\
\hline \multicolumn{4}{l}{ Media Transmisi Link Akses Ke Client } \\
\hline 1 & Kabel LAN Outdoor & 1 & 700.000 & 700.000 \\
& STP/FTP Cat6 1 Roll & & & \\
2 & NetPower 15FR CRS318- & 1 & 2.500 .000 & 2.500 .000 \\
1fi-15fr-2s-out & 2 & 250.000 & 500.000 \\
3 & GPEN11 & 150.000 & 500.000 \\
4 & TPLink WR840N Router & 2 & Total & $\mathbf{4 . 0 0 0 . 0 0 0}$ \\
& \& Wirelles & & Sub Total & $\mathbf{6 . 8 7 5 . 0 0 0}$
\end{tabular}

\begin{tabular}{lllll}
\hline \multicolumn{4}{c}{ Biaya Maintenance } \\
\hline 1 & Crimping Tool Cat 6 & 1 & 240.000 & 240.000 \\
2 & LAN Tester Wire Tracker & 1 & 140.000 & 140.000 \\
& JW-360 & & Sub Total & $\mathbf{3 8 0 . 0 0 0}$ \\
\hline
\end{tabular}

Tabel 3. Analisa Biaya Akses Fiber Optic

\begin{tabular}{|c|c|c|c|c|}
\hline \multicolumn{5}{|c|}{ Media Transmisi Link Akses Ke Server } \\
\hline No & Description & Qty & Harga & Total \\
\hline \multirow[t]{2}{*}{1} & 1 Roll Dropcore 2 core & 1 & 1.100 .000 & 1.100 .000 \\
\hline & $1000 \mathrm{~m}$ fiber optic & & & \\
\hline 2 & ZTE OLT GPON & 1 & 15.400 .000 & 15.400 .000 \\
\hline \multirow{3}{*}{2} & GTGH FTTH ZXA10 & & & \\
\hline & C320 2U Optical & & & \\
\hline & & & Total & 17.600 .000 \\
\hline \multicolumn{5}{|c|}{ Media Transmisi Link Akses Ke Client } \\
\hline \multirow[t]{5}{*}{1} & Modem ONT GPON & & & \\
\hline & ZTE F609 Wirelless & 2 & 500.000 & 1.000 .000 \\
\hline & Router & & & \\
\hline & & & Total & 1.000 .000 \\
\hline & & & Sub Total & 18.600 .000 \\
\hline \multicolumn{5}{|c|}{$\begin{array}{c}\text { Biaya Maintenance } \\
\end{array}$} \\
\hline 1 & Splicer Signal fire Ai 9 & 1 & 15.400 .000 & 15.400 .000 \\
\hline & Fiber Optic & 1 & 450000 & 450000 \\
\hline 2 & Jointwit JW3208 OPM & & 450.000 & \\
\hline \multirow[t]{2}{*}{3} & VFL (Visual Fault & 1 & 350.000 & 350.000 \\
\hline & & & Sub Total & 16.200 .000 \\
\hline
\end{tabular}

\section{B. Rancangan Sistem Baru}

Rancangan sistem baru untuk jaringan internet pada (PUSKOM) IAIN Bengkulu gedung SAINS dan Teknologi dan gedung perpustakaan yang diusulkan dapat dilihat pada jaringan berikut ini :

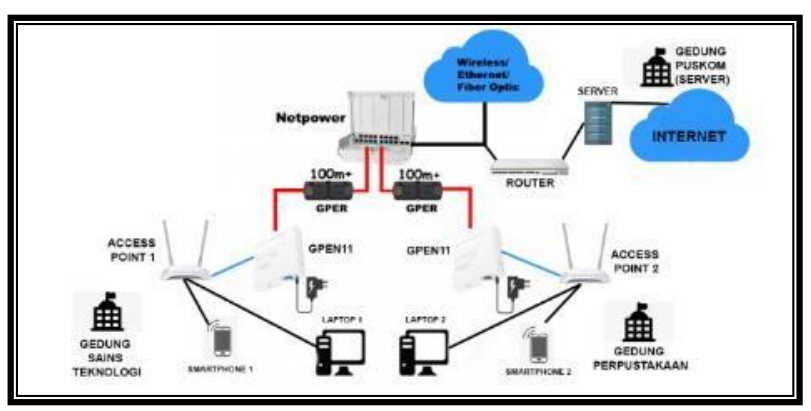

Gambar 9. Rancangan Sistem Baru

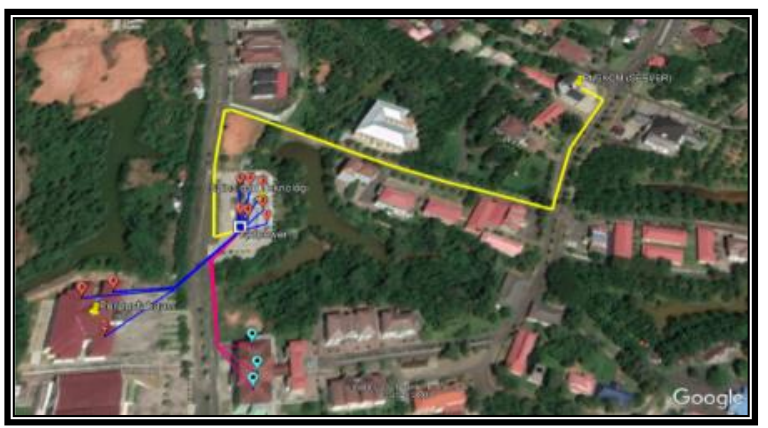




\section{Gambar 10. Rancangan Design Topologi}

\section{Perancangan Rencana Kerja}

Perancangan rencana kerja tidak terlepas dari blok diagram yang merupakan suatu pernyataan gambar yang ringkas, yaitu mulai dari menyiapkan peralatan yang diperlukan, installasi sampai dengan mendapatkan hasil dan kesimpulan dari penggunaan jaringan berteknologi GPEN (Gigabit Passive Ethernet Network). Adapun rencana kerja dapat dilihat pada gambar berikut.

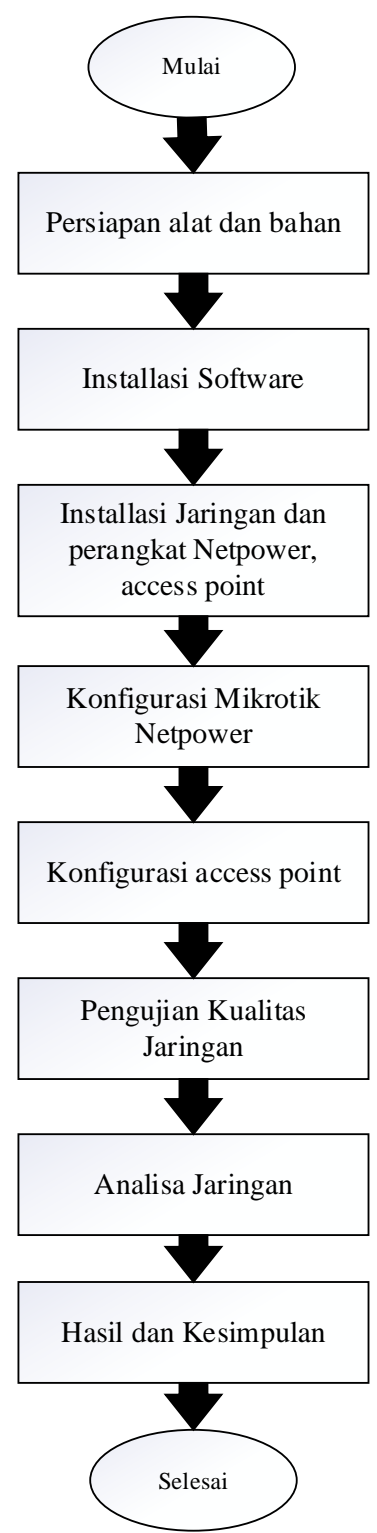

Gambar 10. Rancangan Kerja Sistem

\section{HASIL DAN PEMBAHASAN}

\section{Design Sistem}

Dalam rancangan pengujian hingga implementasi didapatkan hasil penelitian implementasi dan analisa sistem jaringan berteknologi GPEN pada kampus IAIN Bengkulu, sehingga dapat menentukan kelebihan dan kekurangan penggunaan jaringan berteknologi GPEN ini.
Penelitian mengacu pada blok diagram pada bab III dengan mengidentifikasi masalah terlebih dahulu sebelum melakukan implementasi dan analisa sistem jaringan berbasis GPEN pada kampus IAIN Bengkulu, sehingga dapat membantu memanagemen, mengontrol, dan memonitoring pada setiap client.

Tabel 4. Spesifikasi Media Transmisi

\begin{tabular}{|c|c|c|c|}
\hline \multicolumn{4}{|c|}{ Media Transmisi Link Akses Ke Server } \\
\hline No & Description & Volume & Satuan \\
\hline 1 & $\begin{array}{l}\text { Kabel LAN Outdoor STP/FTP } \\
\text { Cat6 } 1 \text { Roll }\end{array}$ & 320 & Meter \\
\hline 2 & $\begin{array}{l}\text { Mikrotik GpeR Gigabit Passive } \\
\text { Ethernet Repater }\end{array}$ & 3 & Pcs \\
\hline \multicolumn{4}{|c|}{ Media Transmisi Link Akses Ke Client } \\
\hline 1 & $\begin{array}{l}\text { Kabel LAN Outdoor STP/FTP link } \\
\text { ke perpustakaan }\end{array}$ & 80 & Meter \\
\hline 2 & $\begin{array}{l}\text { Kabel LAN Outdoor STP/FTP link } \\
\text { ke Sainteklt1 }\end{array}$ & 20 & Meter \\
\hline 3 & $\begin{array}{l}\text { Kabel LAN Outdoor STP/FTP link } \\
\text { ke Sainteklt2 }\end{array}$ & 50 & Meter \\
\hline 4 & Mikrotik Netpower 15FR & 1 & Unit \\
\hline 5 & GPEN11/Power Injector & 2 & Pcs \\
\hline 6 & Tplink WR840N Router Wireless & 3 & Unit \\
\hline
\end{tabular}

Adapun hasil dari implementasi dan analisa sistem jaringan berbasis GPEN ini sangat efektif dan lebih efisien, tujuannya agar bandwith yang didapat lebih stabil dan merubah akses jauh lebih baik dibanding menggunakan jaringan nirkabel dengan radio point to point, tidak perlu khawatir lagi akan gangguan sinyal dan gelombang (interferance), cuaca, serta penghalang antar client server seperti gedung, pepohonan, dan ketingggian . Berikut adalah hasil dari Bandwith test akses dari server ke client yang telah di lakukan :

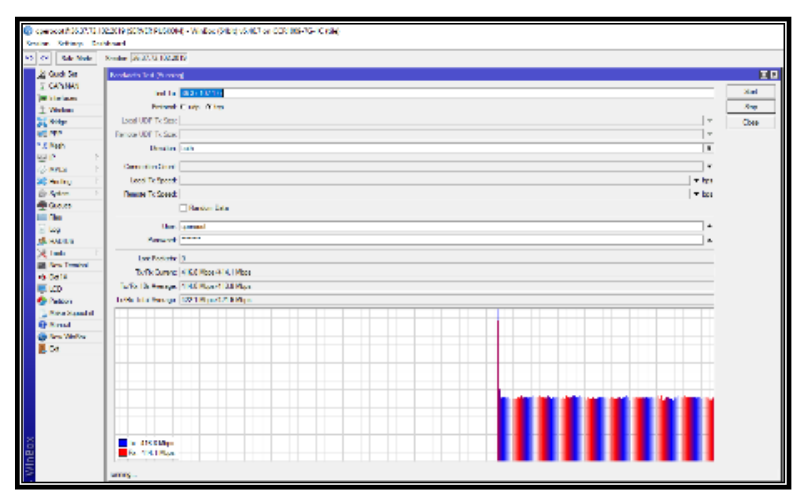

Gambar 11. Traffic Bandwith test GPEN

\section{Implementasi}

\section{A. Konfigurasi Mikrotik}

Untuk mengkoneksikan jaringan internet server ke client pada netpower lite $7 \mathrm{R}$, hal pertama kali yang di lakukan adalah mendownload atau menginstallasi software Switch OS / Winbox v 3.37 (64-bit) untuk 
mengkonfigurasi netpower lite 7R mikrotik ke internet, Juga untuk mengelolah hak akses ,memanagemen dan monitoring. berikut adalah langkah-langkah dalam konfigurasi internet :

1. Login melalui winbox yang telah didownload sebelumnya, pilih Mac Address lalu klik connect

2. Lalu pilih IP Address Masuk ke IP $\rightarrow$ Addresses $\rightarrow$ Klik tanda $+\rightarrow$ lalu isikan IP nya , Isi IP Public/static ke dalam interface Ether1-Internet (sesuai alokasi), Isi IP private 192.168.10.1/24 ke dalam interface Ether2- 4 lalu Ok

3. Kemudian Masuk ke IP $\rightarrow$ Routes $\rightarrow$ Klik tanda $+\rightarrow$ tambahkan default route 0.0.0.0/0 kearah IP gateway Server Puskom lalu Ok

4. Kemudian membuat DHCP Server Masuk ke IP $\rightarrow$ $\mathrm{DHCP}$ Server $\rightarrow$ DHCP $\rightarrow$ Klik tanda $+\rightarrow$ koneksikan ke interface Ether2-4 lalu Ok

5. Kemudian pilih DNS, masukan DNS Google centang pada Allow Remote Request lalu klik Ok

6. Kemudian Masuk ke IP $\rightarrow$ Firewall $\rightarrow$ NAT $\rightarrow$ klik tanda + , pada General Chainya pilih Scrnat dan pada Out internetnya pilih Ether1-Actionya pilih Masquerade, lalu klik Ok

7. Terakhir cek pada menu Terminal, dengan mengetik ping www.google.com

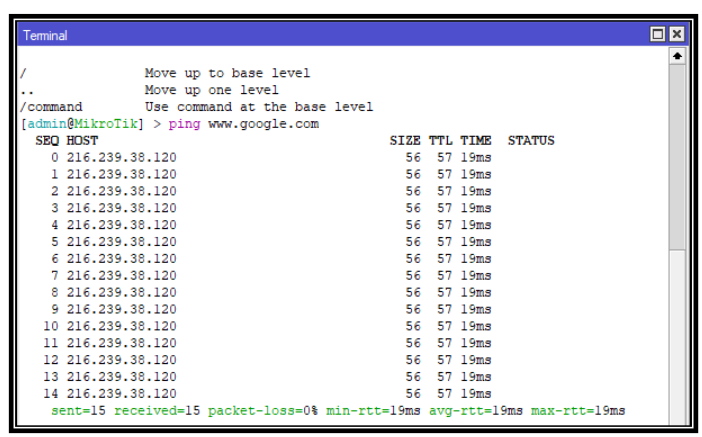

Gambar 12. Pengetesan Ping Internet

\section{B. Konfigurasi Access Point}

1. Langkah pertama adalah menghubungkan kebel UTP dari mikrotik ke access point, setelah itu buka browser dan ketikan IP Default Access Point yaitu 192.168.1.1 masukan user dan password lalu login\}

2. lalu pilih menu pada Quick Setup dan pilih WAN Only klik Next

3. Kemudian pilih Dynamic IP lalu Next, Access Point akan menyesuaikan dengan IP DHCP dari Mikrotik

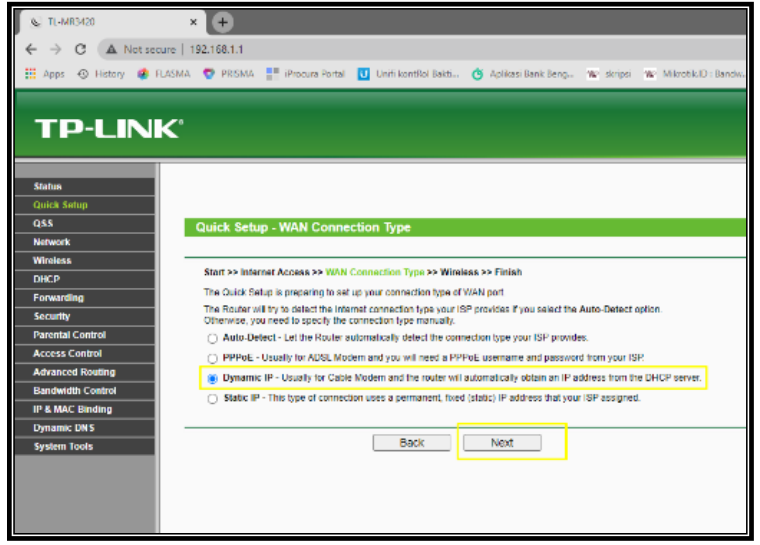

Gambar 13. Tampilan Mode IP Address

4. Kemudian setting SSID dan Password Sesuai dengan keinginan lalu Next, dan perangkat akan merebot

\section{Konfigurasi Sistem Monitoring}

1. Pertama pembuatan bot pada telegram dapat kita lakukan dengan menggunakan @BotFather

2. Selanjutnya untuk dapat mengirim notifikasi kita perlu mencari tahu chat-id bot kita, dapat dilakukan dengan menggunakan@get_id_bot

3. Kemudian remote router kita dan buat sebuah rule Netwatch di menu Tools $\rightarrow$ Netwatch $\rightarrow$ Add Masukan IP yang akan kita monitoring contoh 192.168.10.1/24

4. Masukan script berikut untuk mengirimkan notifikasi ketika host berubah menjadi UP dan Down

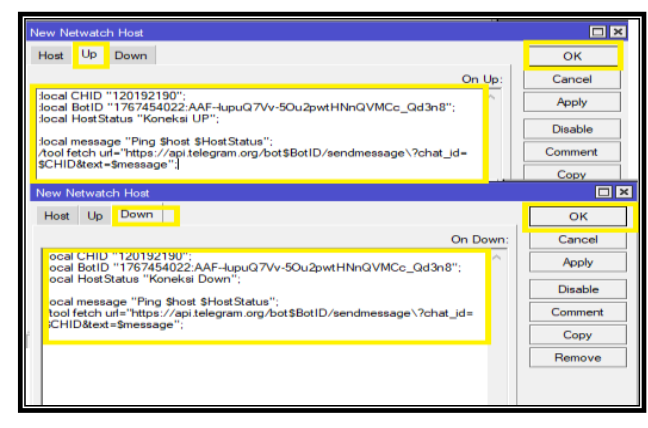

Gambar 14. Tampilan Script

\section{Pengujian}

Pengujian ini dilakukan setelah semua perangkat terhubung dengan menggunakan software Btest Pada mikrotik GPEN Netpower 7R dan Speedtest pada masingmasing access point dengan menggunakan laptop dan smartphone. 
Tabel 5. Tabel hasil pengujian

\begin{tabular}{|c|c|c|c|c|}
\hline No & Interface & $\begin{array}{c}\text { Tx/Rx } \\
\text { Current }\end{array}$ & $\begin{array}{l}\text { Tx/Rx 10s } \\
\text { Averange }\end{array}$ & $\begin{array}{c}\text { Tx/Rx Total } \\
\text { Average }\end{array}$ \\
\hline & \multicolumn{4}{|c|}{ Jumat, 30 April 2021} \\
\hline 1 & $\begin{array}{l}\text { Puskom ke } \\
\text { GPEN } \\
\text { Perpustakaan }\end{array}$ & $\begin{array}{l}\text { 416.8Mbps/ } \\
\text { 411.1 Mbps }\end{array}$ & $\begin{array}{l}\text { 414.0Mbps/ } \\
\text { 413.8 Mbps }\end{array}$ & $\begin{array}{l}\text { 422.1Mbps/ } \\
\text { 421.6 Mbps }\end{array}$ \\
\hline 2 & $\begin{array}{l}\text { GPEN } \\
\text { Perpustakaan } \\
\text { ke Sainteklt1 }\end{array}$ & $\begin{array}{l}99.3 \mathrm{Mbps} / \\
99.1 \mathrm{Mbps}\end{array}$ & $\begin{array}{l}\text { 100.0Mbps/ } \\
\text { 99.9Mbps }\end{array}$ & $\begin{array}{l}\text { 99.9Mbps/ } \\
99.9 \mathrm{Mbps}\end{array}$ \\
\hline \multirow[t]{2}{*}{3} & $\begin{array}{l}\text { GPEN } \\
\text { Perpustakaan } \\
\text { ke Sainteklt2 }\end{array}$ & $\begin{array}{l}99.6 \mathrm{Mbps} / \\
99.8 \mathrm{Mbps}\end{array}$ & $\begin{array}{l}100.1 \mathrm{Mbps} / \\
100.0 \mathrm{Mbps}\end{array}$ & $\begin{array}{l}\text { 99.9Mbps/ } \\
\text { 99.9Mbps }\end{array}$ \\
\hline & \multicolumn{4}{|c|}{ Minggu, 02 Mei 2021} \\
\hline 1 & $\begin{array}{l}\text { Puskom ke } \\
\text { GPEN } \\
\text { Perpustakaan }\end{array}$ & $\begin{array}{l}\text { 420.1Mbps/ } \\
\text { 419.5 Mbps }\end{array}$ & $\begin{array}{l}\text { 415.0Mbps/ } \\
\text { 414.7 Mbps }\end{array}$ & $\begin{array}{l}\text { 422.2Mbps/ } \\
\text { 422.3 Mbps }\end{array}$ \\
\hline 2 & $\begin{array}{l}\text { GPEN } \\
\text { Perpustakaan } \\
\text { ke Sainteklt1 }\end{array}$ & $\begin{array}{l}\text { 99.2Mbps/ } \\
99.8 \mathrm{Mbps}\end{array}$ & $\begin{array}{l}\text { 101.0Mbps/ } \\
100.5 \mathrm{Mbps}\end{array}$ & $\begin{array}{l}\text { 100.0Mbps/ } \\
100.0 \mathrm{Mbps}\end{array}$ \\
\hline \multirow[t]{2}{*}{3} & $\begin{array}{l}\text { GPEN } \\
\text { Perpustakaan } \\
\text { ke Sainteklt2 }\end{array}$ & $\begin{array}{l}\text { 100.2Mbps/ } \\
\text { 99.9Mbps }\end{array}$ & $\begin{array}{l}100.1 \mathrm{Mbps} / \\
100.0 \mathrm{Mbps}\end{array}$ & $\begin{array}{l}99.2 \mathrm{Mbps} / \\
99.4 \mathrm{Mbps}\end{array}$ \\
\hline & \multicolumn{4}{|c|}{ Senin, 03 Mei 2021} \\
\hline 1 & $\begin{array}{l}\text { Puskom ke } \\
\text { GPEN } \\
\text { Perpustakaan }\end{array}$ & $\begin{array}{l}\text { 415.3Mbps/ } \\
\text { 414.6 Mbps }\end{array}$ & $\begin{array}{l}\text { 416.0Mbps/ } \\
\text { 415.3 Mbps }\end{array}$ & $\begin{array}{l}\text { 422.2Mbps/ } \\
\text { 422.3 Mbps }\end{array}$ \\
\hline 2 & $\begin{array}{l}\text { GPEN } \\
\text { Perpustakaan } \\
\text { ke Sainteklt1 }\end{array}$ & $\begin{array}{l}100.1 \mathrm{Mbps} / \\
100.2 \mathrm{Mbps}\end{array}$ & $\begin{array}{l}\text { 100.2Mbps/ } \\
99.5 \mathrm{Mbps}\end{array}$ & $\begin{array}{l}\text { 99.9Mbps/ } \\
\text { 99.7Mbps }\end{array}$ \\
\hline 3 & $\begin{array}{l}\text { GPEN } \\
\text { Perpustakaan } \\
\text { ke Sainteklt2 }\end{array}$ & $\begin{array}{l}99.2 \mathrm{Mbps} / \\
99.6 \mathrm{Mbps}\end{array}$ & $\begin{array}{l}\text { 100.2Mbps/ } \\
100.0 \mathrm{Mbps}\end{array}$ & $\begin{array}{l}99.2 \mathrm{Mbps} / \\
99.6 \mathrm{Mbps}\end{array}$ \\
\hline
\end{tabular}

\section{PENUTUP}

\section{Kesimpulan}

Berdasarkan hasil pengujian dan analisis data penelitian yang telah dilakukan, dapat disumpulkan bahwa terdapat pengaruh yang sangat signifikan terhadap penerapakan Konsep Mikrotik GPEN ini.

1. Konsep mikrotik GPEN ini bisa menjadi solusi interkoneksi dengan biaya yang lebih murah dibandingkan menggunakan Radio Point to Point.

2. Memungkinkan Jaringan yang lebih kecil untuk memberikan layanan serupa seperti GPON dengan biaya yang jauh lebih kecil.

3. Memberi kemudahan saat maintenance, dan menjadi solusi untuk kebutuhan penggunaan user yang lebih banyak tanpa takut lagi kehilangan bandwith dan terganggunya gelombang sinyal frekuensi yang jadi penghalang bagi client server.

\section{Saran}

Setelah dilakukan pengujian dan analisis pada penelitian ini, terdapat beberapa saran agar penelitian sejenis yang akan dilakukan kedepanya mendapatkan hasil yang lebih baik lagi, sebagai berikut :
1. Pengujian dan analisis yang telah dilakukan hanya menggunakan satu ISP (penyedia jasa internet) saja, Karna itu untuk penelitian selanjutnya bisa menggunakan dua ISP agar bisa menjadi backup ketika satu ISP down.

2. Untuk pengembangan penelitian selanjutnya dapat membandingkan teknologi GPEN (Gigabit Passive Ethernet Network) dengan teknologi fiber optik GPON (Gigabit Passive Optic Network).

\section{REFERENSI}

[1] Widodo, A, "Implementasi Monitoring Jaringan Komputer Menggunakan Dude”. Jurnal Teknologi Informasi, 11(1), 1-10, 2015.

[2] Indonesia, K. B, "Pencarian Pengembangan", https://kbbi.kemdikbud.go.id/entri/pengembangan, 2020.

[3] Santoso, \& Nurmaliana, R, "Perencanaan dan Pengembangan Aplikasi Absensi Mahasiswa Menggunakan Smart Card Guna Pengembangan Kampus Cerdas". Jurnal Integrasi, 9(1), 86-87, 2017.

[4] Peraturan Bupati Bantul Nomor 46 Tahun 2019. "Pengembangan dan Pengolahan Infrastruktur Jaringan Pemerintah Kabupaten Bantul”, 2019.

[5] Lubis, I., \& Safii M, "Smart Economy Kota Tanggerang Selatan”, PT Karya Abadi Mitra Indo, tangerang, 2018.

[6] Naiboho, R. S, "Peranan dan Perencanaan Teknologi Informasi dalam Perusahaan". Jurnal Warta Edisi : 52, 2019.

[7] Sofana, I. “Membangun Jaringan Komputer". Bandung: Informatika Bandung, 2015.

[8] Saputro, B, "Manajemen Penelitian Pengembangan (Research \& Development) Bagi Penyusun Tesis dan Disertasi”. Aswaja Pressindo, Yogyakarta, 2017.

[9] Husen, Z., \& Surbakti, S. M, "Membangun Server dan Jaringan Komputer dengan Linux Ubuntu”. Syiah Kuala University Press, Aceh, 2020.

[10] Yuliandoko, H, "Jaringan Komputer Wire dan Wireless Beserta Penerapanya”, Deepublish, Yogyakarta, 2018.

[11] TEKNOLOGI, C. S,"Konsep GPEN (Gigabit Passive Ethernet Network". Diambil kembali dari Mikrotik.id: http://www.mikrotik.co.id/artikel_lihat.php?id=, 2020.

[12] Askari, Z., Afrani, V., \& Zakariah, K. M,. "Metodologi Penelitian Kuantitatif, Kualitatif Action Research and Development ( $R$ and D)". Yayasan Pondok Pesantren AlMawaddah Warrahmah, 2020.

[13] Saputra, B. H., \& Basten, A, "Sistem Jaringan Komputer. Jurnal Universitas Kristen Satya Wacana”, 1-15, 2015. 